\title{
Hydrolysis of Abandoned Bovine Hair by Pulping Spent Liquor and Preparation of Degradable Keratin-based Sprayable Mulch Film
}

\author{
Wenxin Li,* Yurou Chen, and Sufeng Zhang * \\ Pulping spent liquor was used to hydrolyze abandoned bovine hair, and \\ the resulting keratin hydrolyzate was blended with polyvinyl alcohol \\ $(\mathrm{PVOH})$, polyacrylamide (PAM), N,N-methylenebis (acrylamide) (MBA), \\ and glycerol (GL) to prepare the low-cost degradable keratin-based \\ sprayable mulch film (KSMF). The prepared KSMF contained elements \\ required for plant growth, such as $\mathrm{N}, \mathrm{P}, \mathrm{K}, \mathrm{S}, \mathrm{Ca}, \mathrm{Si}$, and the water \\ absorbency reached $380 \%$ in deionized water. A degradation of $23.1 \mathrm{wt} \%$ \\ was attained while it was buried for $50 \mathrm{~d}$ in soil. The KSMF was easy to \\ apply and needed to be diluted for spraying on the soil surface and formed \\ a physical barrier to reduce evaporation of water and heat preservation. \\ The KSMF had good degradability and entered the soil to become a high- \\ quality biomass organic fertilizer during the growth of the crop, thus \\ avoiding "white pollution" and realizing the recycling of waste, which would \\ extend the application prospects in sustainable modern agriculture.
}

\begin{abstract}
Keywords: Abandoned bovine hair; Pulping spent liquor; Hydrolysis; Keratin-based; Sprayable mulch film; Degradable

Contact information: Shaanxi Provincial Key Laboratory of Papermaking Technology and Specialty Paper Development, National Demonstration Center for Experimental Light Chemistry Engineering Education, Key Laboratory of Paper Based Functional Materials of China National Light Industry, Shaanxi University of Science and Technology, Xian 710021, China;

*Corresponding authors: liwx@sust.edu.cn; zhangsufeng@sust.edu.cn
\end{abstract}

\section{INTRODUCTION}

Film mulching technology, which is an effective way to increase the yield of grain in agriculture, is extensively applied to satisfy the increasing food demand due to population growth and limited arable land area (Godfray et al. 2010). Rational use of this technology can effectively reduce the evaporation of water in the soil and promote the growth of crops (Miles et al. 2012; Berger et al. 2013; Li et al. 2014). However, the traditional plastic mulch film used in the film mulching technology is made of nonrenewable petroleum-based resources. The residue of the traditional film remains left on the field and cannot be decomposed by microorganisms, which will lead to decreased soil quality, reduced crop yield (Gu et al. 2017; Hou et al. 2019), and serious "white pollution". Therefore, plastic mulch film needs to be recycled (Briassoulis et al. 2012; Kasirajan and Ngouajio 2012), and many farmers employ centralized stacking or incinerate the plastic mulch film, which will not only cause soil and air pollution, but also affect the health of residents (Hayes et al. 2012; Briassoulis et al. 2015). In recent years, natural polymer materials, which would be an alternative material to meet the needs for mulch film, have attracted increased attention due to their regenerative and degradable properties (Zhao et al. 2016; Yi et al. 2017). Starch-polymer blend films are a hot spot in current research, but 
they are not 100\% degradable (Guilbert and Gontard 2005; Liu 2005) and lead to secondary pollution to the soil. Therefore, it is important to develop a low-cost, degradable mulch film based on renewable resources for agricultural development (Liu et al. 2014).

The main non-water component of papermaking black liquor is lignin, which is the second largest biomass resource in nature after cellulose (Zhang et al. 2019). In addition, pulping spent liquor also contains polypentoses, cellulose, hemicelluloses, and organic matter. If the pulping spent liquor is improperly treated, for example, directly discharged or burned after concentration, it will pollute the environment and lead to a lot of waste of resources (Ragauskas et al. 2014). In addition, lignin contains a variety of reactive groups with ion exchange and chelation properties (Sipponen et al. 2016), and lignin is regarded as a precursor to humus substances, so it can be used as raw material for the preparation of slow-release fertilizers and organic fertilizers, which is conducive to the growth of crops.

At present, due to the development of the leather industry, a large quantity of bovine hair is generated during the processing of leather (Olk et al. 2006; Laurichesse and Avérous 2014; Liu et al. 2015). Abandoned bovine hair is a rich renewable keratin resource (Zhang et al. 2014; Oladele et al. 2018; Valeika et al. 2019), but its use is limited in practice because it generally has a dark color and is resistant to degradation (Gousterova et al. 2005; Lateef et al. 2010). Most of the abandoned bovine hair is landfilled and incinerated, which will cause potential pollution to soil and air (Tesfayel et al. 2017). Hence, it is necessary to develop green and effective methods to recycle these wastes. Studies in recent years indicate that the degradation of keratin by microorganisms is an effective alternative for the management of keratin wastes and for improving their value added (Jayalakshmi et al. 2012). Abandoned bovine hair is a solid protein that is difficult to degrade. However, the liquid protein is obtained after the solid protein is hydrolyzed with disulfide bonds and stable structure are destroyed. At the same time, this protein is full of peptides and easily degraded by microorganisms into amino acids that can provide supplementary nutrients for crops.

In this work, abandoned bovine hair was hydrolyzed by pulping spent liquor, and the novel degradable keratin-based sprayable mulching film (KSMF) was prepared by the mixture solution, which contained keratin hydrolyzate, polyvinyl alcohol (PVOH), polyacrylamide (PAM), N,N-methylenebis (acrylamide) (MBA), and glycerol (GL). In addition, this work explored preparation of a type of low cost and eco-friendly agricultural mulch film based on renewable animal and plant resources. The KSMF became a highquality organic fertilizer after degradation to replace the chemical fertilizer to some extent, which is the necessary direction for the development of modern agriculture. Additionally, it provided effective ways to solve the problems of resource utilization of waste solid protein in tanning, comprehensive utilization of pulping black liquor, and "white pollution" of agricultural film. This not only conforms to the current green development concept, but also achieves sustainable development of agriculture, economy, and environment.

\section{EXPERIMENTAL}

\section{Materials}

Corn stalk pulping spent liquor from cellulose pulp production was obtained from Jilin Province in Northeast China. The black liquor had a $\mathrm{pH}$ of 11 , a solids content of $10.31 \%$, an organic content of $71.35 \mathrm{~g} / \mathrm{L}$, and an effective alkali of $9.29 \mathrm{~g} / \mathrm{L}$. The bovine hair obtained from the hair-saving un-hairing process (Huanghua Defu Leather Co., Ltd., 
Hebei, China) had a keratin content of $81.9 \%$, a fat content of $4.85 \%$, and an ash content of $4.92 \%$. The $\mathrm{KOH}, 30 \mathrm{wt} \%$ hydrogen peroxide $\left(\mathrm{H}_{2} \mathrm{O}_{2}\right)$, PAM, GL, PVOH, and calcium superphosphate were purchased from Tianjin Damao Chemical Reagent Company, Ltd. (Tianjin, China). The MBA was purchased from Tianjin Fuchen Chemical Reagent Company, Ltd. (Tianjin, China). All the chemical reagents were analytical grade.

\section{Bovine Hair Hydrolyzed by Black Liquor}

An appropriate amount of $\mathrm{KOH}, 5 \mathrm{~g}$ of bovine hair, and $50 \mathrm{~mL}$ of black liquor were added to a 250-mL three-necked flask, which was equipped with a mechanical stirrer and reflux condenser. The $\mathrm{KOH}$ was added to increase the $\mathrm{pH}$. After reacting at $95{ }^{\circ} \mathrm{C}$ for $1 \mathrm{~h}$, $30 \mathrm{wt} \% \mathrm{H}_{2} \mathrm{O}_{2}$ was added to the three-necked flask, which oxidized the bovine hair to make the bovine hair fluffy, easy to break, and increased the probability of the bovine hair keratin reaction. Thereby it increased the hydrolysis rate of the bovine hair. After hydrolysis for 5 $\mathrm{h}$, the hydrolysate was filtered, while the residue was filtered off and the filtrate was stored. The mass of the filter residue was optimized for orthogonal experiment. According to the orthogonal table of $\mathrm{L}_{9}(4)^{3}$ (Table 1), the following experiments were conducted. Letter A indicates for the hydrolysis time, whereas B, C, and D stand for the hydrolysis temperature, $\mathrm{KOH}$ dosage, and $\mathrm{H}_{2} \mathrm{O}_{2}$ dosage, respectively. $Q_{\mathrm{fs}}$ stands for the quality of the filter residue.

Table 1. Factors and Levels of Hydrolysis Orthogonal Experiment

\begin{tabular}{|c|c|c|c|c|}
\hline Factor Level & $\mathrm{A}(\mathrm{h})$ & $\mathrm{B}\left({ }^{\circ} \mathrm{C}\right)$ & $\mathrm{C}(\%)$ & $\mathrm{D}(\%)$ \\
\hline 1 & 3 & 85 & 12 & 10 \\
\hline 2 & 4 & 90 & 14 & 12 \\
\hline 3 & 5 & 95 & 16 & 14 \\
\hline
\end{tabular}

A is the hydrolysis time, $\mathrm{B}$ is the hydrolysis temperature, $\mathrm{C}$ is $\mathrm{KOH}$ dosage, $\mathrm{D}$ is $\mathrm{H}_{2} \mathrm{O}_{2}$ dosage, and $Q_{\text {is }}$ is the quality of the filter residue

\section{Preparation of KSMF}

Approximately $20 \mathrm{~mL}$ of the hydrolysate, $1 \mathrm{wt} \% \mathrm{GL}, 0.05 \mathrm{wt} \% \mathrm{MBA}$, and an appropriate amount of PVOH and PAM were added to a 50-mL three-necked flask, which was equipped with a mechanical stirrer and reflux condenser. The mixture solution was obtained after stirring at $95^{\circ} \mathrm{C}$ for $1 \mathrm{~h}$. Next, the mixture solution was filtered to filter out insoluble macromolecular substances, and the filtrate was poured into a Petri dish. The resulting film was uncovered after drying under natural conditions. Then the water absorption performance was measured. The film-forming experiment was conducted according to the orthogonal table of $\mathrm{L}_{9}(3)^{3}$, as shown in Table 2 .

Table 2. Factors and Levels of Preparation of KSMF Orthogonal Experiment

\begin{tabular}{|c|c|c|c|}
\hline Factor Level & $\mathrm{A}(\mathrm{h})$ & $\mathrm{B}(\%)$ & $\mathrm{C}(\%)$ \\
\hline 1 & 1 & 4 & 0.10 \\
\hline 2 & 2 & 6 & 0.15 \\
\hline 3 & 3 & 8 & 1.20 \\
\hline A is the film forming time, $\mathrm{B}$ is PVOH dosage, C is PAM dosage \\
\hline
\end{tabular}

Finally, $\mathrm{Ca}\left(\mathrm{H}_{2} \mathrm{PO}_{4}\right)_{2} \cdot \mathrm{H}_{2} \mathrm{O}$ was used to adjust the $\mathrm{pH}$ of the mixture solution under optimal conditions to neutral to obtain KSMF. Column A indicates the film forming time; column B and C stand for the PVOH dosage and the PAM dosage, respectively. 


\section{Determination of Hydrolysis Rate}

An appropriate amount of bovine hair was weighed $\left(W_{0}\right)$ and hydrolyzed. First, the filter cloth was dried at $65{ }^{\circ} \mathrm{C}$ to constant weight, and the filter cloth weighed $\left(W_{1}\right)$. Next, the hydrolysate was filtered with the filter cloth and the filter residue was washed with deionized water. Finally, the filter cloth and filter residue were baked at $65^{\circ} \mathrm{C}$ for $6 \mathrm{~h}$ and the mass was weighed $\left(W_{2}\right)$. The hydrolysis rate $(H R \%)$ of bovine hair was calculated from Eq. 1,

$$
\operatorname{HR}(\%)=\left[W_{0}-\left(W_{2}-W_{1}\right)\right] / W_{0} \times 100 \%
$$

where $H R \%$ is the hydrolysis rate, $W_{0}(\mathrm{~g})$ is the mass of the dry bovine hair, $W_{1}(\mathrm{~g})$ is the mass of the filter cloth, and $W_{2}(\mathrm{~g})$ is the mass of the filter cloth and the filter residue.

\section{Preparation of KSMF}

Approximately $20 \mathrm{~mL}$ of the hydrolysate, $1 \mathrm{wt} \%$ GL, $0.05 \mathrm{wt} \% \mathrm{MBA}, 8 \mathrm{wt} \%$ $\mathrm{PVOH}$, and $0.20 \mathrm{wt} \%$ PAM were added to a $50-\mathrm{mL}$ three-necked flask, which was equipped with a mechanical stirrer and reflux condenser. The mixture solution was obtained after stirring at $95{ }^{\circ} \mathrm{C}$ for $1 \mathrm{~h}$. Next, the mixture solution was filtered and poured the filtrate into the Petri dish. Finally, the $\mathrm{Ca}\left(\mathrm{H}_{2} \mathrm{PO}_{4}\right)_{2} \cdot \mathrm{H}_{2} \mathrm{O}$ was used to adjust the $\mathrm{pH}$ of the mixture solution to neutral to obtain KSMF.

\section{Material Characterization}

The KSMF was analyzed by pouring the filtrate into the Petri dish and uncovering the film after drying under natural conditions. Scanning electron microscopy (SEM) (Tescan Vega 3 SBH; Tescan, Brno, Czech Republic) and energy dispersive spectrometry (EDS) (Tescan Vega 3 SBH; Tescan, Brno, Czech Republic) were used. Fourier transform infrared (FTIR) spectra were recorded on an infrared spectrometer from $4000 \mathrm{~cm}^{-1}$ to 400 $\mathrm{cm}^{-1}$ (Vertex 70; Bruker, Karlsruhe, Germany). X-ray diffraction (XRD) was recorded on an X-ray diffractometer (D8 Advance; Bruker, Karlsruhe, Germany) by using $\mathrm{Cu} \mathrm{K} \alpha$ radiation at $40 \mathrm{kV}$ and $40 \mathrm{~mA}$. The diffraction angle ranged from $5^{\circ}$ to $75^{\circ}$. Thermogravimetric analysis was measured using a system provided by Mettler Toledo (Netzsch STA 449 F5 TG/DSC; Mettler Toledo, Karlsruhe, Germany) in air at a heat rate of $10^{\circ} \mathrm{C} / \mathrm{min}$ up to $500{ }^{\circ} \mathrm{C}$.

\section{Water Absorption Capacity of KSMF}

The dried film was cut into a size of $2 \mathrm{~cm} \times 2 \mathrm{~cm}$ and weighed $\left(M_{1}\right)$. The sample was immersed in $500 \mathrm{~mL}$ of deionized water for $30 \mathrm{~min}$ at room temperature to absorb water to achieve a swelling equilibrium. The swollen sample was filtered through a 100mesh nylon mesh and suspended for 10 min until there was no free water on the surface and weighed $\left(M_{2}\right)$ (Qiao et al. 2016). The equilibrium water absorption $\left(Q_{\mathrm{eq}}\right)$ was calculated as follows,

$$
\mathrm{Q}_{\mathrm{eq}}(\%)=\left(\mathrm{M}_{2}-\mathrm{M}_{1}\right) / \mathrm{M}_{2}
$$

where $Q_{\text {eq }}(\%)$ is the water absorption, $M_{1}(\mathrm{~g})$ is the mass of the dried film, and $M_{2}(\mathrm{~g})$ is the mass of the film after swelling by water absorption.

\section{Water Retention Capacity of KSMF}

Approximately $50 \mathrm{~g}$ of soil was added to two Petri dishes of the same size and quality. The prepared KSMF was sprayed equally onto the petri dish of the experimental 
group and weighed $\left(G_{01}\right)$. Another Petri dish was used as a control group and weighed $\left(G_{02}\right)$. The Petri dishes were placed at room temperature and the mass of the Petri dishes was weighed $\left(G_{\mathrm{t}}\right)$ at the same time every day for up to $7 \mathrm{~d}$. The mass difference was used as an indicator to compare the evaporation of water (Tang et al. 2017; Cheng et al. 2018). The water retention in soil $\left(G_{\mathrm{wr}}, \mathrm{g}\right)$ can be described as shown in Eq. 3,

$$
\mathrm{G}_{\mathrm{wr}}(\mathrm{g})=\mathrm{G}_{\mathrm{t}}-\mathrm{G}_{0 \mathrm{i}}
$$

where $G_{\mathrm{wr}}(\mathrm{g})$ is water retention capacity, $G_{0 \mathrm{i}}(\mathrm{g})$ is the mass of the Petri dish and soil at beginning, and $G_{\mathrm{t}}(\mathrm{g})$ is the mass of the Petri dish and soil after the same time interval.

\section{Growth Experiments}

Approximately $800 \mathrm{~g}$ of soil were added to the two identical pots, and four wheat seeds were planted in each pot. Then, each pot was watered until moisture seeped out and covered $1 \mathrm{~cm}$ of soil. One pot was used as CK (without KSMF) and the other pot was sprayed with KSMF as the experimental group. Each pot was planted for three groups. The growth of the seeds was observed within $12 \mathrm{~d}$. Then, the roots, leaf length, fresh weight, dry weight, and length of the seeds were measured (Xiang et al. 2018). Each treatment was repeated three times.

\section{Natural Soil Degradation of KSMF}

The degradation behavior was evaluated by measuring the weight loss of KSMF buried in the soil at different times. Approximate $0.1 \mathrm{~g}$ of KSMF was placed in a nylon bag and then buried in a plastic cup $5 \mathrm{~cm}$ below the surface of the soil and incubated for up to $50 \mathrm{~d}$. In the experiment, the soil moisture was kept at $30 \%$ by regular weighing and adding distilled water. At every 5d interval, it was dug out. After being washed carefully with distilled water and dried to constant weight at $65^{\circ} \mathrm{C}$, the KSMF was weighed to determine the weight loss (Liu et al. 2017). The degradation rate $\left(D_{\mathrm{e}} \%\right)$ can be calculated as follows,

$$
\mathrm{D}_{\mathrm{e}}(\%)=\left(\mathrm{Q}_{1}-\mathrm{Q}_{2}\right) / \mathrm{Q}_{1} \times 100 \%
$$

where $D_{\mathrm{e}}(\%)$ is degradation rate, and $Q_{1}$ and $Q_{2}(\mathrm{~g})$ are the weights of the dry KSMF before and after the soil burial $(\mathrm{g})$, respectively.

\section{Statistical Analysis}

Comparisons of various treatments were evaluated using the analysis of variance (ANOVA). Duncan's multiple range tests were used to determine significant differences among treatments $(\mathrm{P}<0.05)$.

\section{RESULTS AND DISCUSSIONS}

\section{Optimization of Hydrolysis Experiment Synthesis Conditions}

When the black liquor was used to hydrolyze the bovine hair, it was necessary to add $\mathrm{KOH}$ due to the alkalinity of the black liquor being insufficient. The $\mathrm{KOH}$ was supplemented, to adjust the composition of the black liquor, increase the $\mathrm{pH}$, and improve the utilization of various components. In addition, $\mathrm{H}_{2} \mathrm{O}_{2}$ promoted the hydrolysis of bovine hair. The mass of the filter residue, which as an indicator to optimize the hydrolysis experiment, was filtered by keratin hydrolysate. The weight of the residue was less, which further indicated that lignin generated hydrogen bonds with the amino acid in the 
hydrolysate to form a macromolecular polymer. Orthogonal experiments with four factors and three levels were performed to find suitable conditions for bovine hair hydrolyzed by black liquor.

The composition of black liquor is complicated, but the main component is lignin. During the hydrolysis process, hydrophilic groups in the hydrolysate was increased. At the same time, lignin and keratin formed a large molecular chain due to hydrogen bonding between the reactive groups. The analysis results are exhibited in Table 3 . The factors affecting the hydrolysis rate were $\mathrm{C}>\mathrm{B}>\mathrm{A}>\mathrm{D}$. The dosage of $\mathrm{KOH}$ had the greatest influence on the hydrolysis rate, the hydrolysis temperature degree followed, then the hydrolysis time, and the dosage of $\mathrm{H}_{2} \mathrm{O}_{2}$ was last. The optimal experimental combination was $\mathrm{A}_{3} \mathrm{~B}_{3} \mathrm{C}_{3} \mathrm{D}_{2}$, and the corresponding conditions were as follows: the hydrolysis temperature of $95{ }^{\circ} \mathrm{C}$, the hydrolysis time of $5 \mathrm{~h}, \mathrm{KOH}$ dosage of $16 \%$, and $\mathrm{H}_{2} \mathrm{O}_{2}$ dosage of $12 \%$. Under those conditions, the quantity of the filter residue was $1.158 \mathrm{~g}$. The hydrolysis percentage was $76.8 \%$.

\section{Optimization of KSMF Synthesis Conditions}

The water absorption properties of the film were different under different film forming conditions. To seek the optimal water absorption of the film, the three-factor and three-level orthogonal experiments were set up, and the analysis results are exhibited in Table 4. Factor A indicates the film forming time, B indicates $\mathrm{PVOH}$ dosage, $\mathrm{C}$ indicates PAM dosage, and $Q_{\text {eq }}$ indicates equilibrium water absorption. The factors affecting the water absorption were $\mathrm{B}>\mathrm{C}>\mathrm{A}$. The dosage of $\mathrm{PVOH}$ had the greatest influence on the water absorption, the dosage of PAM followed, and the reaction time was last. The optimal experimental combination was $\mathrm{A}_{1} \mathrm{~B}_{3} \mathrm{C}_{3}$, and the corresponding conditions were as follows: $1 \%$ of glycerol dosage, $0.05 \%$ of MBA dosage, $8 \%$ of PVOH dosage, $0.20 \%$ of PAM dosage, and $1 \mathrm{~h}$ reaction time, the water absorbency reached $380 \%$ in deionized water.

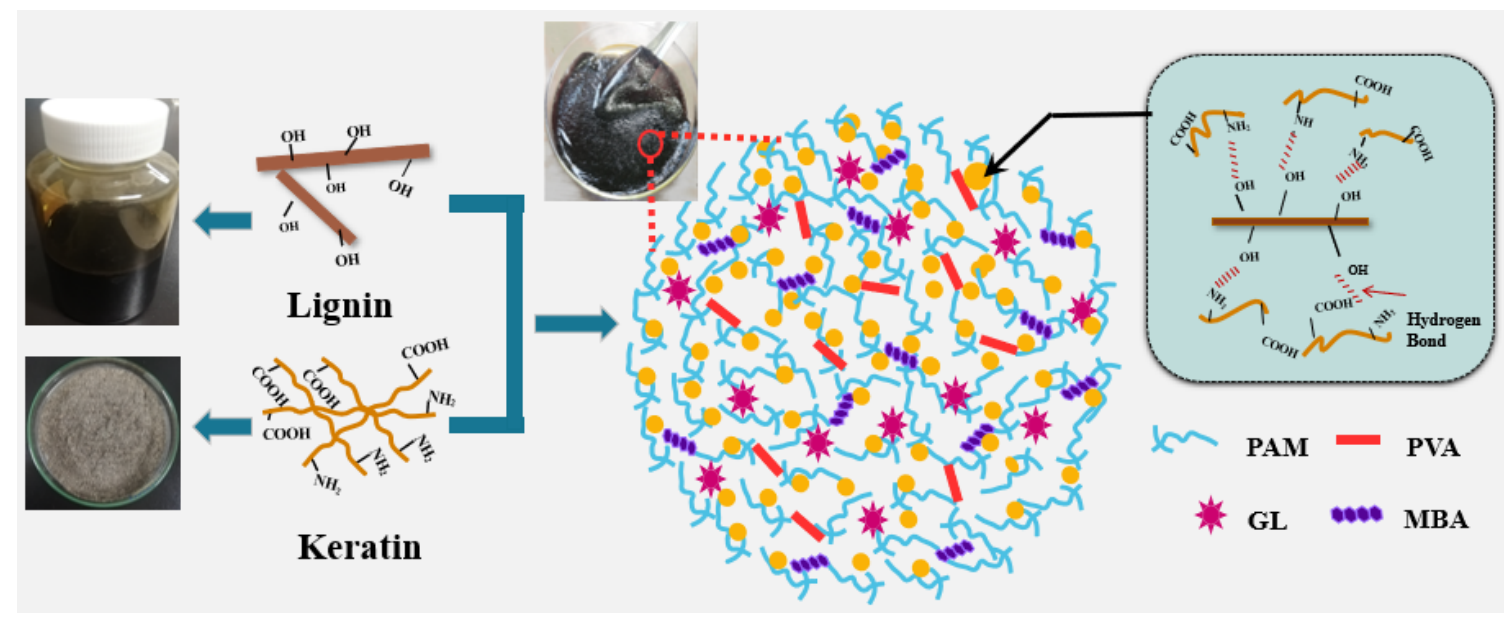

Fig. 1. Schematic diagram for the preparation of the KSMF

The PVOH has good film forming and adhesion properties, and PAM has excellent water absorption, adhesion, and film forming properties. The swelling ratio of KSMF reached approximately $380 \%$ after drying and immersion in deionized water. This indicated that KSMF had excellent water absorption and contributes to the growth of crops. This may be because the molecular chain formed by hydrolysis, the polymers of PVOH and PAM were crosslinked by the crosslinking action of the crosslinking agent MBA and 
the physical entanglement of PVOH to form a relatively stable three-dimensional network polymer macromolecular structure. Additionally, a small amount of GL was added as plasticizer to enhance the film forming property to make the film dense. Therefore, the novel degradable keratin-based sprayable mulch film was obtained, which had good properties of warming, water retention, and water absorption. The schematic diagram for KSMF is shown in Fig. 1.

\section{Water Retention of KSMF in Soil}

The sprayable mulch film is a macromolecular polymer, and its functional groups and active sites in the soil can combine effectively to reduce the evaporation of water. The spraying process of KSMF is shown in Fig. 2(a).

(a)

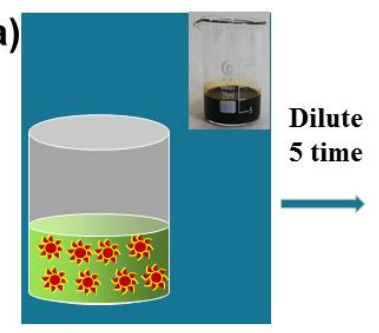

(b)

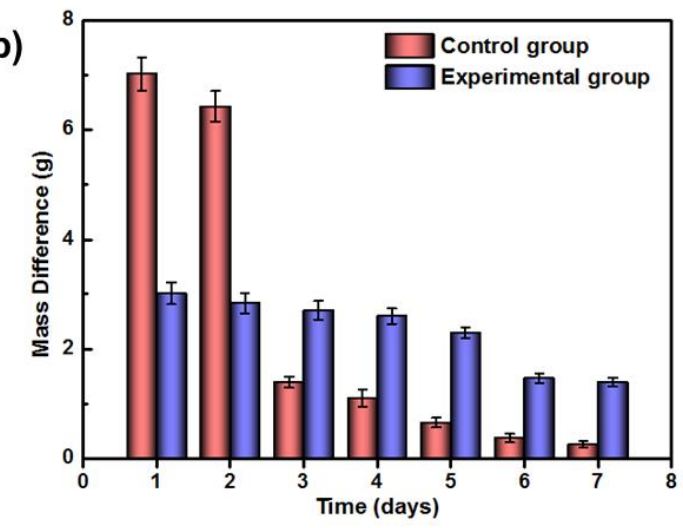

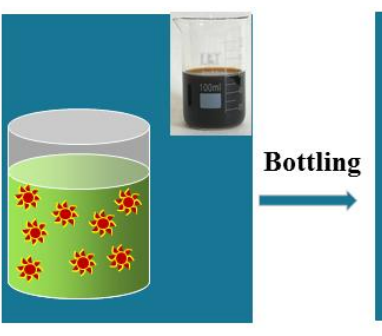

(c)

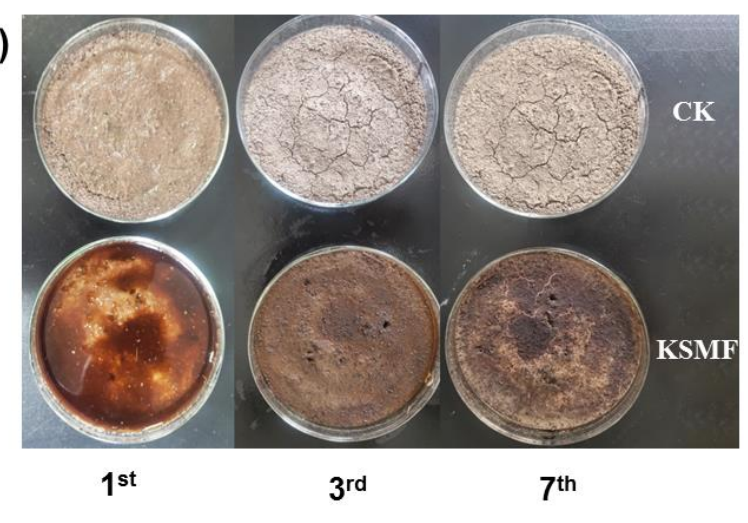

Fig. 2. (a) Spraying process of the KSMF, (b) the mass of soil and Petri dish over time, and (c) water retention of KSMF and $\mathrm{CK}$ at the same time interval

The KSMF was diluted according to the required concentration and sprayed on the soil surface. It combined with the soil particles on the soil surface, and then the soil particles were bridged by various chemical interactions, thereby promoting the collection of soil particles. Figure 2(b) shows that with the increase of time, the Petri dish without spraying the KSMF volatilized a large amount of water in two days before experiment, and the volatilization rate of moisture was extremely fast. In contrast, the Petri dish with the sprayed KSMF volatilized less water and the volatilization of water was slower. It can be observed from Fig. 2(c) that the surface particles on the soil surface were bound tightly to form a physical barrier to resist the volatilization of water on the soil surface. Additionally, the soil of KSMF was still wet on the 7th day, while the soil of CK was dry and cracked on the $3^{\text {rd }}$ day. Therefore, it can be concluded that the application of KSMF could retain and supply moisture for plants and reduce water consumption. 


\section{FTIR Analysis}

Figure 3(a) shows the FTIR spectra of keratin, lignin, hydrolysate, and KSMF. The characteristic absorption peaks were observed at $1660 \mathrm{~cm}^{-1}$ and $1542 \mathrm{~cm}^{-1}$ for the bending of the Amide I band and Amide II band. The characteristic peaks in the lignin spectra were attributed to the following: the peak at $3475 \mathrm{~cm}^{-1}$ corresponded to the $-\mathrm{OH}$ stretching vibration, and the characteristic absorption of $1610 \mathrm{~cm}^{-1}$ and $1514 \mathrm{~cm}^{-1}$ could be ascribed to the aromatic nucleus and lilac nucleus.
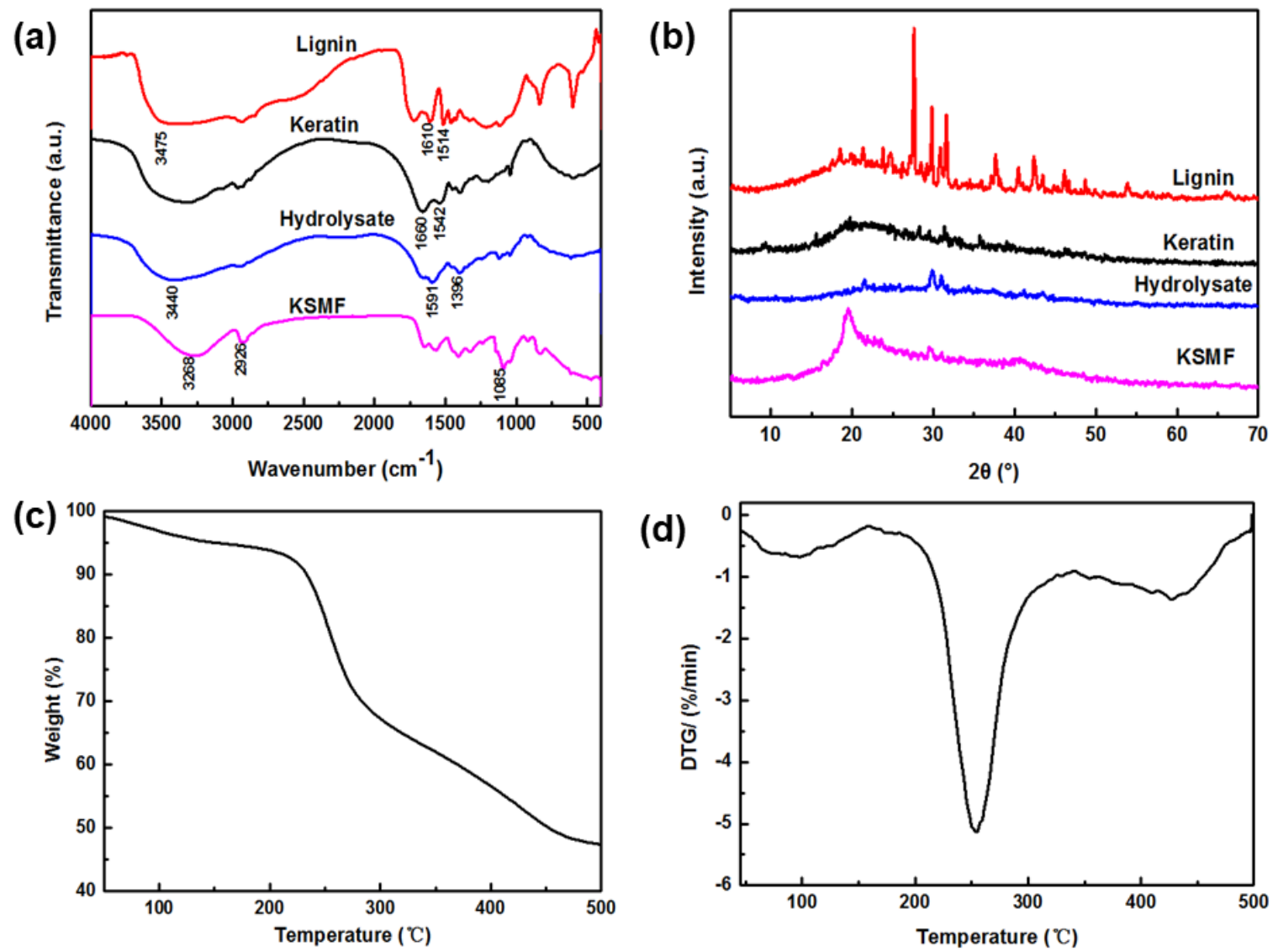

Fig. 3. (a) FTIR spectra of keratin, lignin, hydrolysate, and KSMF, (b) XRD patterns of keratin, lignin, hydrolysate, and KSMF, (c) Thermogravimetric curves of KSMF, and (d) Derivative thermogravimetric curves of KSMF

For hydrolysate, the characteristic absorption peak at $3440 \mathrm{~cm}^{-1}$ was assigned to the -OH stretching vibration, which was wider than that of keratin and lignin. This may be due to the formation of hydrogen bonds between lignin and keratin during hydrolysis. Moreover, compared with keratin, the characteristic absorption peak of the Amide I band and Amide II band were weakened and redshifted from $1660 \mathrm{~cm}^{-1}$ and $1542 \mathrm{~cm}^{-1}$ to 1591 $\mathrm{cm}^{-1}$ and $1396 \mathrm{~cm}^{-1}$. This indicated that the bovine hair was dissolved in the black liquor, and the lignin in the black liquor interacted with the keratin molecules to improve the compatibility of the two components.

For KSMF, the characteristic absorption peak at $3268 \mathrm{~cm}^{-1}$ could be attributed to the $-\mathrm{OH}$ stretching vibration. The $-\mathrm{OH}$ stretching vibration, compared with hydrolysate, was strengthened and redshifted from $3440 \mathrm{~cm}^{-1}$ to $3268 \mathrm{~cm}^{-1}$. This may be due to the polymerization, which would result in the formation of the three-dimensional network. 
Additionally, the peak at $2926 \mathrm{~cm}^{-1}$ and $1084 \mathrm{~cm}^{-1}$ could be assigned to the $-\mathrm{CH}_{2}$ and $\mathrm{C}-\mathrm{O}$ stretching of $\mathrm{PVOH}$, respectively, indicating that $\mathrm{PVOH}$ penetrated successfully into the three-dimensional network of KSMF. Taken together, these results confirm the formation of KSMF material.

\section{XRD Analysis}

Figure 3(b) shows the XRD patterns of keratin, lignin, hydrolysate, and KSMF. For keratin, it was an amorphous substance. For lignin, the characteristic peaks at $2 \theta=27.60^{\circ}$, $29.86^{\circ}$, and $31.57^{\circ}$ indicated that lignin was a crystalline phase structure. For hydrolysate, the characteristic peaks at $2 \theta=29.86^{\circ}$ and $30.99^{\circ}$ confirmed the hydrolysate had the same crystal as lignin. Moreover, the hydrolysate showed a characteristic peak at $2 \theta=21.52^{\circ}$, indicating that the bovine hair participated in the dissolution reaction, interacted with lignin and influenced the structure and crystallinity of lignin. It was noteworthy that KSMF appeared as one strong, broad peak at approximately $2 \theta=19.58^{\circ}$. This result may be due to the macromolecules in the solution that were crosslinked together by polymerization. It also proved that keratin and lignin in KSMF had a good combination, rather than simple physical blending. This was consistent with the FTIR analysis results.

\section{Thermogravimetric (TG)-Derivative Thermogravimetric (DTG) Analysis of KSMF}

The TG and DTG curves of KSMF are shown in Fig. 3(c) and (d). It can be seen from Fig. 2 that there was a slight weight loss phenomenon below $157^{\circ} \mathrm{C}$, which may have been due to the loss of moisture. The temperature ranged from 157 to $371{ }^{\circ} \mathrm{C}$, wherein severe weight loss occurred, with weight losses of $31.3 \%$. Within the temperature range from 371 to $500{ }^{\circ} \mathrm{C}$, a slight weight loss occurred with weight losses of $15.83 \%$. It could be because there was hydrogen bonding between lignin and keratin as well as copolymerization, which led the macromolecules to be crosslinked together, thereby improving the thermal stability of KSMF.

\section{Degradation of KSMF in Soil}

As shown in Fig. 4, the increased weight loss with prolongation of time demonstrated the degradability of the KSMF (Wen et al. 2017). The surface of the soil buried sample was coarse and loose. Comparing Fig. 4(a) and (b), many dots and cracks emerged on the surface of the KSMF buried in soil after $50 \mathrm{~d}$. The main reason was that lignin was degraded into low molecular weight phenol compounds with an increase in burial time (Sipponen et al. 2016).

The small molecule peptides obtained after the abandoned bovine hair had been hydrolyzed were a good source of microbial nutrition and energy for microorganisms; they boosted the microbial activities in the soil, and accelerated the degradation of KSMF (Shavandi et al. 2017; Adelere and Lateef 2019). As shown in Fig. 4(c), the degradation rate of KSMF buried in soil after $50 \mathrm{~d}$ was $23.1 \%$. Lignin and the keratin hydrolyzate belonged to biomass materials with good degradability, which made KSMF eco-friendly. Therefore, the prepared KSMF can be regarded as a low-cost and degradable sprayable mulch film. 
(a)

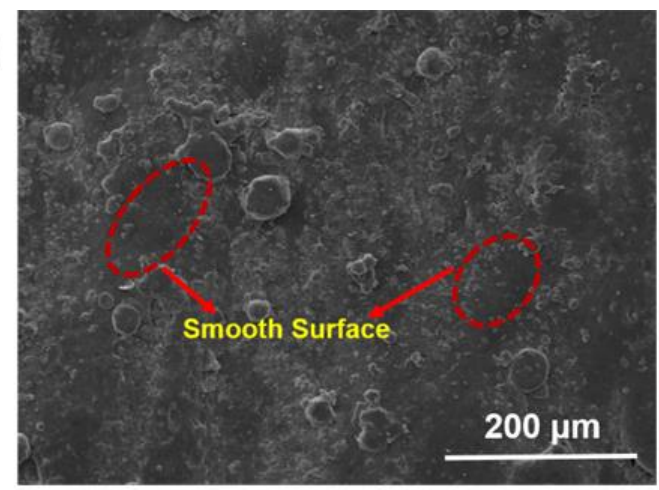

(c)

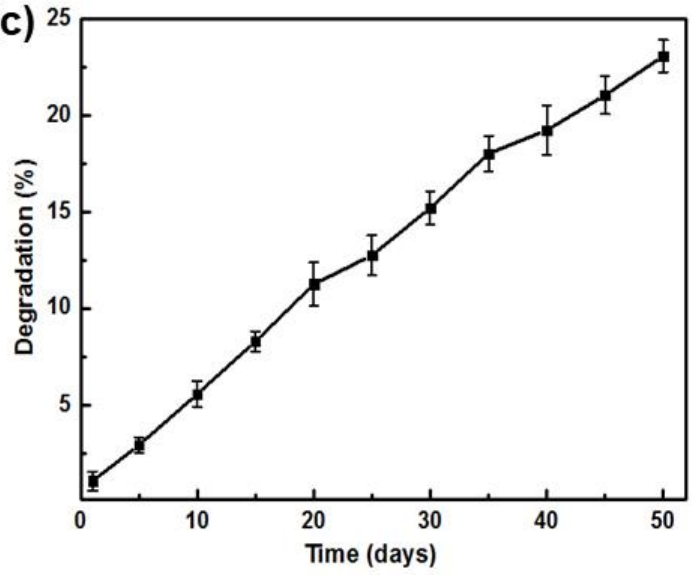

(b)
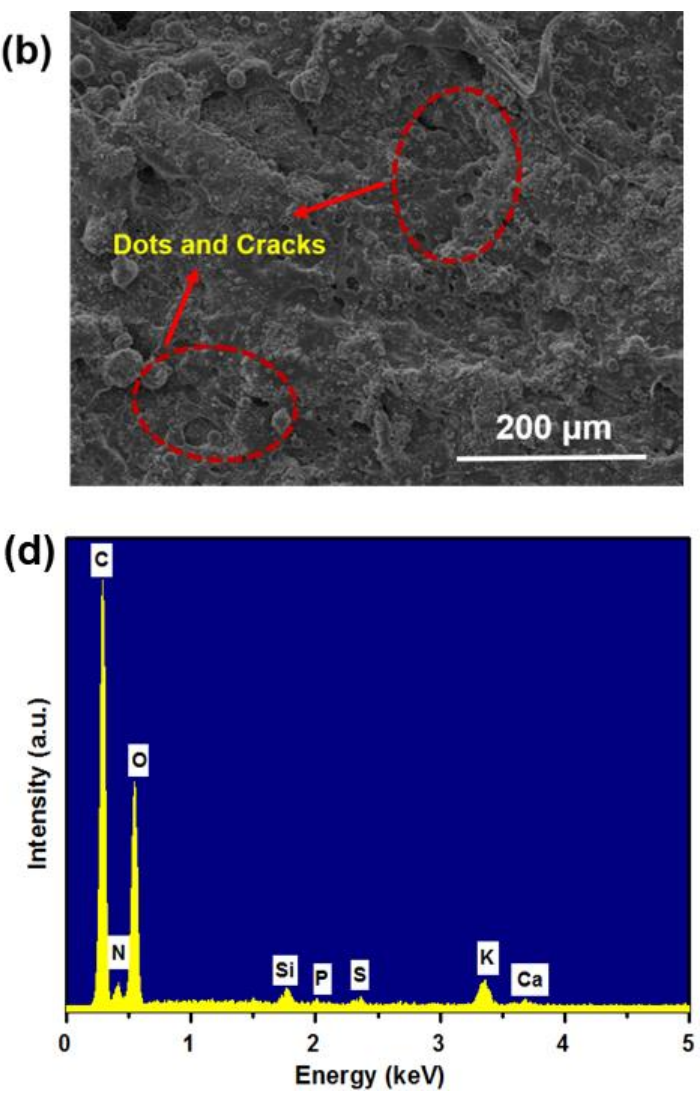

Fig. 4. SEM images of KSMF: (a) before degradation ( $0 \mathrm{~d})$, (b) surface morphologies of the KSMF buried in soil after $50 \mathrm{~d}$, (c) degradation rates of KSMF, and (d) EDS spectra of KSMF

\section{Growth Experiment}

As shown in Fig. 4(d), KSMF contains elements required for plant growth such as N, P, K, S, Ca, and Si. As shown in Fig. 5(a), the height of the wheat seeds in the CK was much lower than that in the KSMF after $12 \mathrm{~d}$. The wheat leaves sprayed with KSMF were firmer and thicker than those of the unsprayed group. As shown in Fig. 5(b) and Table 3, the average fresh weight of wheat sprayed with KSMF was $0.339 \mathrm{~g}$, the average dry weight was $0.065 \mathrm{~g}$, the root length was $9.975 \mathrm{~cm}$, and the average length of the trunk was 16.000 $\mathrm{cm}$. The reason for this was the low molecular weight phenolic compounds after lignin degradation, which improved soil fertility and created favorable conditions for plant growth. At the same time, the keratin hydrolyzate obtained after abandoned bovine hair was hydrolyzed, which contain amino acids, provided nutrition for the growth of plants. These results indicated that the prepared KSMF had the function of promoting seed development and root growth.

Table 3. Average Fresh Weight, Dry Weight, Root Length, and Leaf Length of Wheat in $\mathrm{CK}$ and KSMF

\begin{tabular}{|c|c|c|c|c|}
\hline Sample & $\begin{array}{c}\text { Fresh Weight } \\
(\mathrm{g})\end{array}$ & $\begin{array}{c}\text { Dry Weight } \\
(\mathrm{g})\end{array}$ & $\begin{array}{c}\text { Root Length } \\
(\mathrm{cm})\end{array}$ & $\begin{array}{c}\text { Stem Length } \\
(\mathrm{cm})\end{array}$ \\
\hline CK & $0.25 \pm 0.04$ & $0.04 \pm 0.01$ & $9.08 \pm 0.08$ & $14.78 \pm 1.10$ \\
\hline KSMF & $0.34 \pm 0.06$ & $0.07 \pm 0.02$ & $9.98 \pm 0.07$ & $16.00 \pm 1.23$ \\
\hline
\end{tabular}



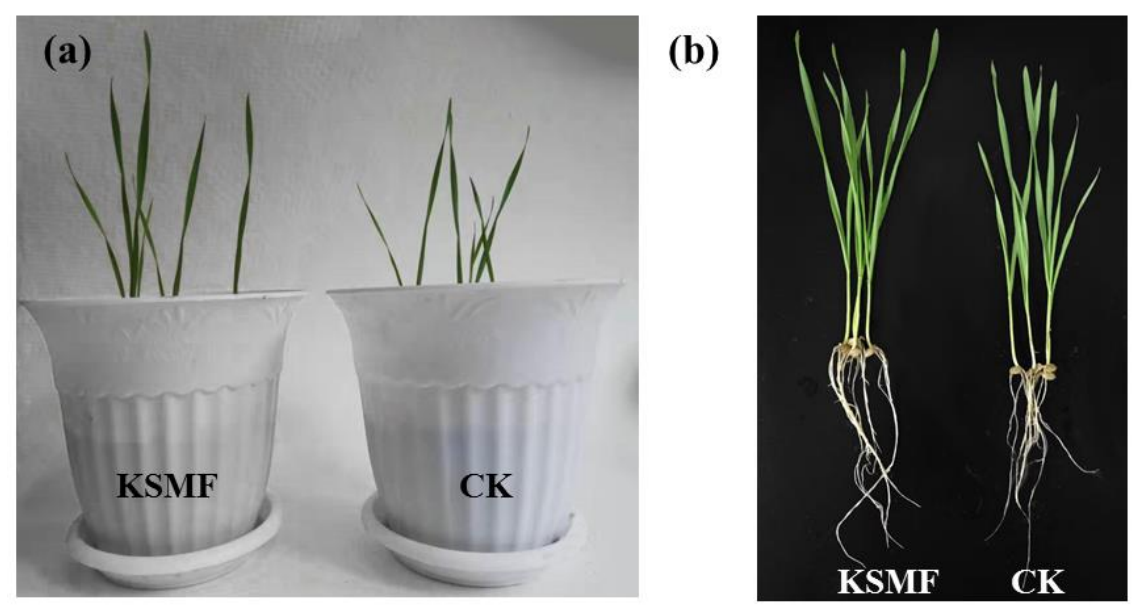

Fig. 5. (a) Wheat growth after $12 \mathrm{~d}$ and (b) the wheat was pulled out after $12 \mathrm{~d}$

\section{CONCLUSIONS}

In this work, corn stalk pulping spent liquor and abandoned bovine hair from leather processing were used as low-cost sources to prepare a novel degradable keratin-based sprayable mulch film. The KSMF is sprayed on the soil surface and forms a physical barrier to prevent the evaporation of water. This does not prevent the seedlings of the plant from passing through the film layer. At the same time, KSMF contains natural protein and lignin, and directly enters the soil, and is degraded by microorganisms during the growth of the crop, becoming a high-quality biomass organic fertilizer. In addition, KSMF can improve the physical and chemical properties of the soil, promote the growth of crops, and have the same application effects (water retention and warming effects) as the plastic mulch film, and can also reduce the "white pollution". This can help to solve the problem of the resource utilization of waste keratin in tanning and provide a new method for the comprehensive application of pulping spent liquor, reduce the "white pollution", thereby achieve sustainable green development of agriculture and economy.

\section{ACKNOWLEDGMENTS}

This study was supported by the Key Scientific Research Plan (Key Laboratory) of Shaanxi Provincial Education Department (17JS016) and the International Joint Research Center for Biomass Chemistry and Materials, Shaanxi International Science and Technology Cooperation Base (2018GHJD-19).

\section{REFERENCES CITED}

Adelere, I. A., and Lateef, A. (2019). "Degradation of Keratin Biomass by Different Microorganisms," in: Keratin as a Protein Biopolymer, S. Sharma and A. Kumar (eds.), Switzerland, pp. 123-162. 
Berger, S., Kim, Y., Kettering, J., and Gebauer, G. (2013). "Plastic mulching in agriculture-friend or foe of $\mathrm{N}_{2} \mathrm{O}$ emissions," Agr. Ecosyst. Environ. 167(1), 43-51. DOI: 10.1016/j.agee.2013.01.010

Briassoulis, D., Hiskakis, M., Babou, E., Antiohos, S. K., and Papadi, C. (2012). "Experimental investigation of the quality characteristics of agricultural plastic wastes regarding their recycling and energy recovery potential," Waste Manage. 32(6), 1075-1090. DOI: 10.1016/j.wasman.2012.01.018

Briassoulis, D., Babou, E., Hiskakis, M., and Kyrikou, I. (2015). “Analysis of long-term degradation behaviour of polyethylene mulching films with pro-oxidants under real cultivation and soil burial conditions," Environ. Sci. Pollut. Res. 22(4), 2584-2598. DOI: $10.1007 / \mathrm{s} 11356-014-3464-9$

Cheng, D. D., Liu, Y., Yang, G. T., and Zhang, A. P. (2018). "Water-and fertilizerintegrated hydrogel derived from the polymerization of acrylic acid and urea as a slow-release N fertilizer and water retention in agriculture," J. Agr. Food Chem. 66(23), 5762-5769. DOI: 10.1021/acs.jafc.8b00872

Guilbert, S., and Gontard, N. (2005). "Agro-polymers for edible and biodegradable films: Review of agricultural polymeric materials, physical and mechanical characteristics," in: Innovations in Food Packaging, J. H. Han (ed.), New York, NY, USA, pp. 263276.

Godfray, H. C. J., Beddington, J. R., Crute, I. R., Lawrence, H., Lawrence, D., Muir, J. F., Pretty, J., Robinson, S., Thoms, S. M., and Toulmin, C. (2010). "Food security: The challenge of feeding 9 billion people," Science 327(5967), 812-818. DOI: 10.1126/science. 1185383

Gousterova, A., Braikova, D., Goshev, I., Christov, P., Tishinov, K., Tonkova, V.E., Haertle, T., and Nedkov, P. (2005). "Degradation of keratin and collagen containing wastes by newly isolated thermoactinomycetes or by alkaline hydrolysis," Lett. Appl. Microbiol. 40(5), 335-340. DOI: 10.1111/j.1472-765X.2005.01692.X

Gu, X. B., Li, Y. N., and Du, Y. D. (2017). "Biodegradable film mulching improves soil temperature, moisture and seed yield of winter oilseed rape (Brassica napus L.)," Soil Tillage Res. 171, 42-50. DOI: 10.1016/j.still.2017.04.008

Hayes, D. G., Dharmalingam, S., Wadsworth, L. C., Leonas, K. K., Miles, C., and Inglis, D. A. (2012). "Biodegradable agricultural mulches derived from biopolymers," ACS Sym. Ser. 1114, 201-223. DOI: 10.1021/bk-2012-1114.ch013

Hou, L., Xi, J., Chen, X. T., Li, X. W., Ma, W., Lu, J. K., Xu, J., and Lin, Y. B. (2019). "Biodegradability and ecological impacts of polyethylene-based mulching film at agricultural environment," J. Hazard. Mater. 378, Article ID 120774. DOI: 10.1016/ j.jhazmat.2019.120774

Jayalakshmi, T., Krishnamoorthy, P., Kumar, G. R., Sivamani, P., and Lakshmi, C. G. A. (2012). "Application of pure keratinase on keratinous fibers to identify the keratinolytic activity," J. Chem. Pharmaceut. Res. 4(6), 3229-3233.

Lateef, A., Oloke, J. K., Kana, E. B. G., Sobowale, B. O., Ajao, S.O., and Bello, B.Y. (2010). "Keratinolytic activities of a new feather-degrading isolate of Bacillus cereus LAU 08 isolated from Nigerian soil," Int. Biodeter. Biodegr. 64(2),162-165. DOI: org/10.1016/j.ibiod.2009.12.007

Laurichesse, S., and Avérous, L. (2014). "Chemical modification of lignins: Towards biobased polymers," Prog. Polym. Sci. 39(7), 1266-1290. DOI:

10.1016/j.progpolymsci.2013.11.004 
Li, C., Moore-Kucera, J., Lee, J., Corbin, A., Brodhagen, M., Miles, C., and Inglis, D. (2014). "Effects of biodegradable mulch on soil quality," Appl. Soil Ecol. 79, 59-69. DOI: 10.1016/j.apsoil.2014.02.012

Liu, Z. Q. (2005). "Edible films and coatings from starches," in: Innovations in Food Packaging, J. H. Han (ed.), New York, NY, USA, pp. 318-337.

Liu, E. K., He, W. Q., and Yan, C. R. (2014). "'White revolution' to 'white pollution'Agricultural plastic film mulch in China," Environ. Res. Lett. 9(9), Article ID 091001. DOI: $10.1088 / 1748-9326 / 9 / 9 / 091001$

Liu, W., Zhou, R., Zhou, D., Ding, G., Soah, J. M., Yue, C. Y., and Lu, X. (2015). "Lignin-assisted direct exfoliation of graphite to graphene in aqueous media and its application in polymer composites," Carbon 83, 188-197. DOI: 10.1016/j.carbon.2014.11.036

Liu, X. Q., Yang, Y. C., Gao, B., Li, Y. C., and Wang, Y. S. (2017). "Environmentally friendly slow-release urea fertilizers based on waste frying oil for sustained nutrient release," ACS Sustain. Chem. Eng. 5(7), 6036-6045. DOI: 10.1021/acssuschemeng.7b00882

Miles, C., Wallace, R., Wszelaki, A., Martin, J., Cowan, J., Walters, T., and Inglis, D. (2012). "Deterioration of potentially biodegradable alternatives to black plastic mulch in three tomato production regions," HortScience 47(9), 1270-1277. DOI: 10.21273/HORTSCI.47.9.1270

Oladele, I. O., Agbeboh, N. I., Omokafe, S. M., and Ibrahim, O. I. (2018). "Effects of fiber fraction on the mechanical and abrasion properties of treated bovine hair fiber reinforced polyester composites," Tribology in Industry 40(2), 254-262. DOI: 10.24874/ti.2018.40.02.09

Qiao, D. L., Liu, H. S., Yu, L., Bao, X. Y., Simonb, G. P., Petinakisc, E., and Chen, L. (2016). "Preparation and characterization of slow-release fertilizer encapsulated by starch-based superabsorbent polymer," Carbohyd. Polym. 147, 146-154. DOI: 10.1016/j.carbpol.2016.04.010

Olk, D. C., Cassman, K. G., Schmidt-Rohr, K., Anders, M. M., Mao, J. D., and Deenik, J. L. (2006). "Chemical stabilization of soil organic nitrogen by phenolic lignin residues in anaerobic agro-ecosvstems," Soil Biol. Biochem. 38, 3303-3312. DOI: 10.1016/j.soilbio.2006.04.009

Ragauskas, A. J., Beckham, G. T., Biddy, M. J., Chandra, R., Chen, F., Davis, M. F., Davison, B. H., Dixon, R. A. Gilna, P., and Keller, M., et al. (2014). "Lignin valorization: Improving lignin processing in the biorefinery," Science 344(6185), Article ID 1246843. DOI: $10.1126 /$ science. 1246843

Shavandi, A., Silva, T. H., Bekhit, A. A., and Bekhit, A. E. A. (2017). "Keratin: Dissolution, extraction and biomedical application," Biomater Sci. 5(9), 1699-1735. DOI: $10.1039 / \mathrm{c} 7 \mathrm{bm} 00411 \mathrm{~g}$

Sipponen, M. H., Rojas, O. J., Pihlajaniemi, V., Lintinen, K., and Sterberg, M. O. (2016). "Calcium chelation of lignin from pulping spent liquor for water-resistant slowrelease urea fertilizer systems," ACS Sustain. Chem. Eng. 5(1), 1054-1061. DOI: 10.1021/acssuschemeng.6b02348

Tang, Y. F., Wang, X. Y., Yang, Y. C., Bin Gao, B., Wan, Y. S., Li, Y. C. C., and Chen, D. D. (2017). "Activated lignite-based super large granular slow-release fertilizers improve apple tree growth: Synthesis, characterizations, and laboratory and field evaluations," J. Agr. Food Chem. 65(29), Article number 5879. DOI: 10.1021/acs.jafc.7b01699 
Tesfayel, T., Sithole, B., and Ramjugernath, D. (2017). "Valorisation of chicken feathers: A review on recycling and recovery route-current status and future prospects," Clean Technol. Envir. 19(10), 2363-2378. DOI: 10.1007/s10098-017-1443-9

Valeika, V., Širvaitytè, J., Bridžiuvienė, D., and Švedienėet, J. (2019). “An application of advanced hair-save processes in leather industry as the reason of formation of keratinous waste: Few peculiarities of its utilization," Environ. Sci. Pollut. Res. 26(6), 6223-6233. DOI: 10.1007/s11356-019-04142-0

Wen, P., Wu, Z. S., Han, Y. J., Cravotto, G., Wang, J., and Ye, B. C. (2017). "Microwave-assisted synthesis of a novel biochar-based slow-release nitrogen fertilizer with enhanced water-retention capacity," ACS Sustain. Chem. Eng. 5(8), 7374-7382. DOI: 10.1021/acssuschemeng.7b01721

Xiang, Y., Ru, X. D., Shi, J. G., Jiang Song, J., Zhao, H. D., Liu, Y. Q., and Zhao, G. Z. (2018). "Granular, slow-release fertilizer from urea-formaldehyde, ammonium polyphosphate, and amorphous silica gel: A new strategy using cold extrusion," $J$. Agr. Food Chem. 66(29), 7606-7615. DOI: 10.1021/acs.jafc.8b02349

Yi, X. L., He, W., Zhang, X. D., Yue, Y. Z., Yang, G. H., Wang, Z. Y., Zhou, M. J., and Wang, L. Z. (2017). "Graphene-like carbon sheet/Fe3O4 nanocomposites derived from soda paperforming black liquor for high performance lithium ion batteries," Electrochim. Acta 232, 550-560. DOI: 10.1016/j.electacta.2017.02.130

Zhang, Y., Liang, X. Y., Yang, X. G., Liu, H. Y., and Yao, J. M. (2014). “An ecofriendly slow-release urea fertilizer based on waste mulberry branches for potential agriculture and horticulture applications," ACS Sustain. Chem. Eng. 2(7), 1871-1878. DOI: $10.1021 / \mathrm{sc} 500204 \mathrm{z}$

Zhang, L., Zhang, S., Yang, J., Chi, C., and Wang, Q. (2019). "Pore surface fractal characterization in waste cotton-derived carbon materials and the effect of pyrolysis conditions on the level of sulfonation," BioResources 14(3), 6633-6644. DOI: 10.15376/biores.14.3.6633-6644

Zhao, Z., Cannon, F. S., Nieto-Delgado, C., and Pena, L. D. (2016). "Lignin/collagen hybrid biomaterials as binder substitute for specialty graphites and electrodes," Carbon 108, 303-317. DOI: 10.1016/j.carbon.2016.07.026

Article submitted: February 27, 2020; Peer review completed: April 18, 2020; Revised version received and accepted: May 10, 2020; Published: May 14, 2020.

DOI: 10.15376/biores.15.3.5058-5071 